\title{
STUDY OF BACTERIAL BIOFILM FORMATION ON A THERMOPLASTIC BIOCOMPOSITE WITH POLYPROPYLENE REINFORCED SHORT ALFA FIBERS USED IN DENTAL PROSTHESES
}

\author{
Maryama Essajii ${ }^{1}$, Fatiha Rhrich ${ }^{2}$, Mariam Benhadou ${ }^{3}$, \\ Jamal Mouslim ${ }^{1}$, Abdellah Haddout ${ }^{3}$ \\ ${ }^{1}$ Ecology and Environment Laboratory, Applied Microbiology Team, \\ Ben M'sik Faculty of Sciences, University Hassan II- Casablanca, Morocco \\ ${ }^{2}$ Laboratory of Odontological Sciences, Oral Biology Team, Faculty of Dentistry, \\ University Hassan II- Casablanca, Morocco \\ ${ }^{3}$ Laboratory of Industrial Management and Energy and Technology of Plastics and \\ Composites - ENSEM Casablanca, University Hassan II- Casablanca, Morocco
}

\begin{abstract}
Bio-composites with vegetal reinforcement have experienced great industrial development in various sectors of activity such as: automotive, electronics, medical, or construction. Compared with synthetic fibers, plant fibers have numerous environmental, technical, processing, economic and health advantages. With the objective of application in the dental field, we present in this paper the study of bacterial adhesion on a biomaterial composite with polypropylene reinforced vegetable fibers extracted from the Alfa plant (stepa tenassicma).

For this study, two strains of bacteria from the oral bacterial flora were chosen, Lactobacillus acidophilus and Streptococcus mutans, and analyzed by spectrophotometric method.

The results analysis shows clearly the formation of biofilm by bacterial adhesion is remarkable in the presence of the composite not reinforced by vegetable fibers in comparison with the biocomposite reinforced by Alfa fibers, and more remarkably formed by the strain Streptococcus mutans than with the strain Lactobacillus acidophilus.
\end{abstract}

Keywords: Biocomposite, Dental prostheses, Alfa fibers, Bacterial formation.

Cite this Article: Maryama Essajii, Fatiha Rhrich, Mariam Benhadou, Jamal Mouslim, Abdellah Haddout, Study of Bacterial Biofilm Formation on a Thermoplastic Biocomposite with Polypropylene Reinforced Short Alfa Fibers used in Dental Prostheses, International Journal of Mechanical Engineering and Technology (IJMET), 12(7), 2021, pp. 43-48.

https://iaeme.com/Home/issue/IJMET?Volume=12\&Issue=7 
Study of Bacterial Biofilm Formation on a Thermoplastic Biocomposite with Polypropylene

Reinforced Short Alfa Fibers used in Dental Prostheses

\section{INTRODUCTION}

Biocomposites made from plant fibers have many environmental, technical, economic and health advantages that industries could benefit from. Thermoplastic biocomposites based on plant fibers are developing in several activities with many industrial applications [1]. Biomaterials are defined as "all non-living materials used in a medical device intended to interact with biological systems"[2].

Thermoplastic biocomposites based on Alfa fibers can find their applications in several fields such as the automotive industry or in dentistry, in particular the manufacture of removable dental appliances [1]. These materials must have certain physicochemical and mechanical properties as well as biocompatibility to guarantee their correct functioning [2].

Mechanical studies represent a very important step in understanding Alfa's strengths in the form of fibers: its qualities and the possibility of becoming one of the most used fibrous plants in the biocomposites industry [3].

The objective of this work is the demonstration of bacterial biofilm formation by strains of the oral cavity on the surface of a thermoplastic biocomposite with polypropylene reinforced short Alfa fibers, with the aim of its use in the manufacture dental prostheses.

The bacterial ecosystem of the oral cavity is the most complex in the body. It is home to several species of microorganisms: Bacteria, yeasts, protozoa and viruses. Its bacterial diversity will require finding in this medium favorable adhesion surfaces (biofilm formation), rich and varied nutritive and respiratory conditions, and physicochemical factors compatible with this flora in order to live and develop [4]. Its bacterial diversity will require finding in this medium favorable adhesion surfaces (biofilm formation), rich and varied nutritive and respiratory conditions, physicochemical factors compatible with this flora in order to live and develop [4].

Oral biofilm contains a complex bacterial organism. The formation of these early stages begins with a deposition of glycoproteins on the surfaces of soft tissues and hard tissues imbued with saliva by inducing cariogenesis. Infectious oral diseases caused by tooth decay are manifested by acid demineralization of bacterial origin. The three bacterial genera that have been shown to have cariogenic properties in humans are Streptococcus, Lactobacillus and Actinomyces [5].

\section{MATERIALS AND METHODS}

The thermoplastic used in our composites is an isotactic polypropylene with a density of $0.905 \mathrm{~g} / \mathrm{cm}^{3}$ and a hot melt index of $12 \mathrm{~g} / 10 \mathrm{~min}$ at $230^{\circ} \mathrm{C}$ and $2.16 \mathrm{~kg}$ (according to the ISO1133 standard).

The short Alfa fiber / thermoplastic polymer blend and coupling agent and additives were extruded and granulated in our laboratory using an extruder. The profile of the extruder screws is suitable for compounding composites according to a defined standard. Using a design of experiments, we performed an in-depth study for the definition and optimization of the injection molding conditions of composites.

\subsection{Test Strains}

The bacterial strains used in this work are cariogenic species: Streptococcus mutans and Lactobacillus acidophilus. These species were obtained from the oral biology laboratory of Faculty of Dentistry of Casablanca. 


\subsection{Condition and Culture Medium}

A bacterial solution was prepared from a colony of each bacterial strain in $5 \mathrm{ml}$ of LB medium of $\mathrm{Ph}=7$, composed of: Tryptophan $10 \mathrm{~g}+$ Yeast extract $5 \mathrm{~g}+\mathrm{NaCl} 10 \mathrm{~g}$ mixed in 1 liter of distilled water. The optical density of the bacterial solution (SB) obtained is:

Lactobacillus acidophilus DO600 $=0.266$, and Streptococcus mutans DO600 =0.107.

In test tubes containing separately $0.5 \mathrm{ml}$ of $\mathrm{SB}$ and $4.5 \mathrm{ml}$ of LB medium, of which:

Lactobacillus acidophilus DO600 $=0.060$, and Streptococcus mutans DO600 $=0.051$.

A $1 \mathrm{~cm}^{3}$ sample of the studied biocomposite (Polypropylene reinforced with short Alfa fibers) of $0 \%$ and $30 \%$ fibers. At the same time, a culture of Lb. acidophilus and Sp. mutans was made without material.

Incubation was carried out anaerobically for 7 days at $37^{\circ} \mathrm{C}$. Each condition was performed in triplicate.

Samples of the studied biocomposite of $1 \mathrm{~cm} 3$ (Polypropylene reinforced with short Alfa fibers) with $0 \%$ and $30 \%$ fibers are incubated. At the same time, a culture of Lb. acidophilus and Sp. mutans was made without material.

Incubation was carried out anaerobically for 7 days at $37^{\circ} \mathrm{C}$. Each condition was performed in triplicate.

\subsection{Results Extraction}

After the tubes incubation, the example of studied materials were taken, impregnated in $5 \mathrm{ml}$ of sterile distilled water, then they are washed in $5 \mathrm{ml}$ of sterile distilled water followed by repeated stirring for 10min in order to release the bacteria (adherent) that have formed a biofilm on the surface of the material. As for the fonts and the sizes of the headings, this manuscript in itself constitutes a good example.

The measurement of the optical density (OD) with wavelength of $600 \mathrm{~nm}$ was carried out to assay the adherent bacteria recovered in sterile distilled water and the non-adherent (free) bacteria in culture solution, each strain separately and for all samples of the material.

\section{RESULTS AND DISCUSSION}

After the strains incubation, two fractions of bacteria were obtained; a free fraction in the culture solution and a fraction adhered to the polypropylene surface with different levels of Alfa fibers recovered in sterile distilled water, then the results were obtained by spectrophotometry, these are presented in the tables following indicating the OD values for each sample.

Table 1 Cultures of bacteria without material

\begin{tabular}{|l|c|}
\hline \multicolumn{1}{|c|}{ Strains } & $\begin{array}{c}\text { Optical density } \\
\text { Rating values }\end{array}$ \\
\hline Sp. mutans & 0.698 \\
\hline Lb. Acidophilus & 3.04 \\
\hline
\end{tabular}

Table 2 OD of the free and adhered fractions of the cultures of Sp. Mutans

\begin{tabular}{|l|c|c|}
\hline & $\begin{array}{c}\text { Free } \\
\text { fraction }\end{array}$ & $\begin{array}{c}\text { Adhered } \\
\text { fraction }\end{array}$ \\
\hline $\begin{array}{l}\text { PP+ 0\% Short } \\
\text { Alfa fibers }\end{array}$ & 0.108 & 0.281 \\
\hline $\begin{array}{l}\text { PP+ 30\% Short } \\
\text { Alfa fibers }\end{array}$ & 0.222 & 0.181 \\
\hline
\end{tabular}


Study of Bacterial Biofilm Formation on a Thermoplastic Biocomposite with Polypropylene Reinforced Short Alfa Fibers used in Dental Prostheses

Table 3 OD of the free and adhered fractions of the cultures of Lb. Acidophilus

\begin{tabular}{|l|c|c|}
\hline & $\begin{array}{c}\text { Free } \\
\text { fraction }\end{array}$ & $\begin{array}{c}\text { Adhered } \\
\text { fraction }\end{array}$ \\
\hline $\begin{array}{l}\text { PP+ 0\% Short } \\
\text { Alfa fibers }\end{array}$ & 2.95 & 0.214 \\
\hline $\begin{array}{l}\text { PP+ 30\% Short } \\
\text { Alfa fibers }\end{array}$ & 2.56 & 0.164 \\
\hline
\end{tabular}

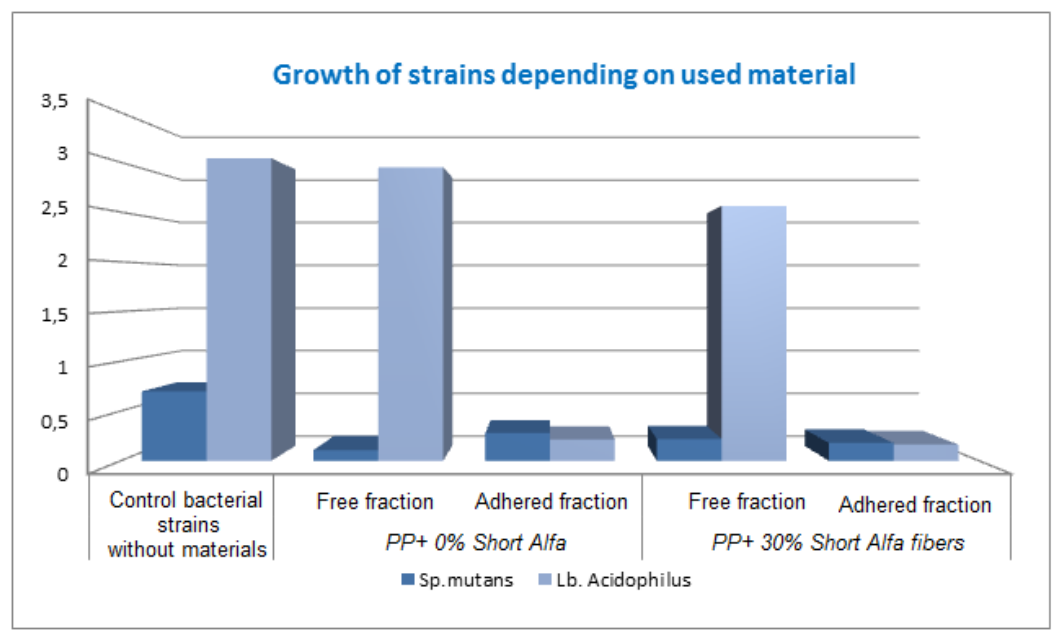

Figure 1 Growth of strains depending on used material

\subsection{Bacteria without Materials}

The optical density (OD) of the two control bacterial strains incubated without materials shows the concentration of bacteria in solution (free) with a value of 0.698 in Sp. Mutans and 3.04 Lb. Acidophilus.

\subsection{Polypropylene 0\% Short Alfa fiber}

The incubation of Lb. Acidophilus with $0 \%$ polypropylene of short Alfa fibers showed a large increase in free bacteria, but a low concentration of adherent bacteria. In parallel for Sp. Mutans it was found that the growth of the adherent bacteria is slightly high compared to the control sample, but the free bacteria have low growth. Therefore, biofilm formation on the surface of short Alfa fiber reinforced biomaterial with a percentage of $0 \%$ was significant in strain Sp. Mutans compared to strain Lb. Acidophilus.

\subsection{Polypropylene $30 \%$ / Short Alfa fiber}

At Lb. Acidophilus, we noticed a high concentration of free bacteria; on the other hand we found that the growth of adherent bacteria is very low. For the Sp. Mutans strain, the concentration of free bacteria was approximately equal to that of adherent bacteria but with a low value compared to the control.

Biofilm formation on the surface of short Alfa fiber reinforced biomaterial with a percentage of $30 \%$, was remarkably very low in both strains.

\subsection{Discussion}

The oral cavity provides a space for perpetual interaction. It contains several structures, such as mucous membranes, enamel, saliva, restorative materials and commensal. The distribution of bacteria in the oral ecosystem depends on ecological factors which are: anatomo-histological 
(hard substrate: tooth; soft substrate: oral mucosa), physicochemical (temperature, redox potential, $\mathrm{pH}$, dissolved gas, etc.) or nutritional [5]. There is essentially a supragingival flora (Streptococcus sobrinus, S. mutans, S. sanguis, S. mitis, S. salivarius, Lactobacillus sp., Actinomycessp., A. viscosus) and a subgingival flora closely related to the supragingival gingival mainly composed of strict anaerobic Gram-negative microorganisms (Porphyromonas gingivalis, Prevotellainte rmedia, Fusobacterium nucleatum, Campylobacter rectus...) [6].

The bacteria of the supragingival flora will be the origin of the acid demineralization of dental hard tissues, while the subgingival flora responsible for periodontal disease [7].

For our study, we chose two strains of supragingival bacteria:

- S. mutans is one of the quantitatively dominant streptococci in human oral flora. It synthesizes extracellular polysaccharides from salivary sucrose. Numerous studies have shown the etiological role of this microorganism in caries [8], [9], [10].

- Lb. Acidophilus are: Gram-positive, rectilinear or curved bacilli of varying length and thickness, immobile, facultative rod-shaped anaerobic, non-sporulating and mostly non-capsulated, acidtolerant, catalase-negative [5].

\section{CONCLUSION}

The aim of this work is to study firstly the formation of biofilm by the adhesion of the two oral bacterial strains on polypropylene reinforced short alfa fibers biocomposite, secondly to compare the adhesion of the two strains chosen according to the materials used (polypropylene / Alfa).

The results of the optical density of the different samples showed that the biofilm formation by the two strains was high on the non-reinforced polypropylene, and less on the polypropylene reinforced with $30 \%$ of fiber. Therefore, it can be concluded that the reinforcement of polypropylene biocomposite with short Alfa fibers makes possible to have a material that promotes the lowers adhesion of bacteria and the biofilm formation mainly in the bacteria presence sp. Mutan strain. These strains are primary colonizers which initiate the oral biofilm formation and then promote interactions with secondary colonizers such as the Lactobacillus species, which is involved in acidogenicity, aciduria and finally enamel demineralization [7]. The Lb. Acidophilus have poor adhesion to smooth surfaces. This explains their preferential location in the furrows and the triturating tooth surfaces. Among the different factors of S. mutans involved in biofilm formation: the glucansucrase which synthesizes sucrose-dependent glucans (important for cell adhesion and biofilm formation) [5].

\section{REFERENCES}

[1] F. Rhrich, F. Bourzgui, M. Benhadou, A. Haddout, Biocomposite with polypropylene and alfa fibers: structure/ properties relationship. International Journal of Mechanical Engineering and Technology (IJMET) Volume 6, Issue 10, Oct 2015, pp. 145-153.

[2] C. Dupas, A. Gaudin, D. Perrin, D. Marion, Etanchéité des obturations coronaires. Encycl Med Chir Odontol,2008, 23-063-F-10:1-10.

[3] M. Essajii, F. Rhrich, M. Benhadou, J. Mouslim, A. Haddout, Morphological and thermomechanical characterization of injected bio composites with polypropylene reinforced by short alfa fibers. International Journal of Mechanical Engineering and Technology (IJMET) Volume 10, Issue 12, December 2019, pp. 390-398.

[4] A. Roberts, Bacteria in the mouth. Dent. Update 32, 2005, 134-136, 139-140, 142. https://doi.org/10.12968/denu.2005.32.3.134 
Study of Bacterial Biofilm Formation on a Thermoplastic Biocomposite with Polypropylene

Reinforced Short Alfa Fibers used in Dental Prostheses

[5] M. Sixou, A. Diouf, D. Alvares, Biofilm buccal et pathologies buccodentaires. Antibiotiques 9 , 2007, 181-188. https://doi.org/10.1016/S1294-5501(07)91377-1

[6] B. krasse, The proportional distribution of Streptococcus salivarius and other streptococci in various parts of the mouth. Odontol Rev 1954, 5 : 203-11.

[7] HM Eriksen, V Dimitrov, M Rohlin, et al. The oral ecosystem: implications for education. Eur J Dent Educ, 10: 192-6, 2006.

[8] W.H. Bowen, H. Koo, Biology of Streptococcus mutans-Derived Glucosyltransferases: Role in Extracellular Matrix Formation of Cariogenic Biofilms. Caries Res. 45, 2011, 69-86.

[9] PI Diaz, NI Chalmers, AH Rickard, et al. Molecular characterization of subject-specific oral microflora during initial colonization of enamel. Appl Environ Microbiol 2006, 72 : 2837-48.

[10] SS Socransky, SD Manganiello. The oral microbiota of man from birth to senility. J Periodontol 1971; 42: 485-96. 